City University of New York (CUNY) CUNY Academic Works

\title{
An "Anti-Handbook Handbook" for Unexpected Changes in a Library Organization
}

Stephanie M. Margolin

Hunter College

Malin Abrahamsson

CUNY Hunter College

\section{How does access to this work benefit you? Let us know!}

More information about this work at: https://academicworks.cuny.edu/hc_pubs/682

Discover additional works at: https://academicworks.cuny.edu

This work is made publicly available by the City University of New York (CUNY).

Contact: AcademicWorks@cuny.edu 


\section{FEATURE: WORTH NOTING}

\section{An “Anti-Handbook Handbook" for Unexpected Changes in a Library}

\section{Organization}

Stephanie Margolin and Malin Abrahamsson

abstract: Library employees face countless changes, big and small, in their workplaces every day: not only the COVID-19 pandemic but also such commonplace events as open positions, renovations, budget cuts, and new library systems. No single handbook can anticipate all the changing needs. This case study discusses how one particular library responded, in a specific time and context. The librarians and staff created a model of self-leadership in an effort to articulate a shared purpose and to establish cohesion and well-being in a group that was sometimes divided and stressed. Lessons learned include the importance of ways of thinking, rather than specific protocols, and the value of trust, listening, and transparency.

$$
\text { Why an "Anti-Handbook"? [A head] }
$$

This case study describes an academic library led by an interim dean during an international pandemic that shuttered the parent institution. All library services were either adapted to remote access or temporarily discontinued. While these circumstances are unusually dramatic, library employees face hundreds of small changes in their workplaces every day, some anticipated and some not. Frequently, they must adjust to open positions (through resignation, retirement, or attrition), renovations and construction projects, changes in institutional administration, and budget cuts that necessitate reductions in staffing or materials. At times, libraries face imposed reorganizations, at other times, new library systems and tools. In all cases, libraries will benefit from an alert response by their leaders and employees, and a shared commitment to being 
adaptable. No single handbook or set of guidelines can anticipate all the changing needs of any library, regardless of size. Instead, this case study shows how one library responded, in a specific time and context. The lessons learned, and shared here, involve mindsets or ways of thinking rather than specific protocols to follow. Leadership change can be initiated at any level of the library, and there is real value in supporting —and participating in—such initiatives. This article is written for any and all library workers, not strictly for library leaders. Different readers will have different takeaways; the article is intended to serve as an inspiration or a spark to action rather than a specific plan for what to do.

\section{The Inspiration for Internal Leadership [A head]}

In this case study, the authors reflect on leadership that is both internal and, in many cases, not officially recognized within the library or by the larger institution. The process of developing a new strategy for internal leadership began in response to a series of unexpected changes that required the library to operate under three different deans (alternating with the same interim dean) in less than five years. ${ }^{1}$

A large cohort of library faculty and staff organized themselves and began meeting in the summer following the departure of the first dean. Together, this group articulated a shared desire for improved internal communications and greater transparency. In these meetings, library workers truly came together; not only did a diversity of voices from a variety of ranks choose to speak, but also faculty and staff chose to travel from four different library locations to attend.

When a second dean was named and then resigned within a year, the staff group saw an opportunity to create structural change, revising their library's bylaws to create a more inclusive decision-making process. Changes included expanded participation of both faculty and staff in 
department meetings and developing a committee structure that was open to all library employees.

This work on internal leadership still goes on. The interim dean now serving for the fourth time is a longtime colleague who has provided abundant opportunities for growth and leadership development, even among people who are not formally recognized for their roles. The new internal leadership system faced a trial by fire under the changes of dean and the COVID pandemic. . While responding to the pandemic and its subsequent impact on the institution at large (including orders to work remotely), this library staff group also adapted to the retirement of a unit head with decades of institutional experience, a significant budget cut and hiring freeze, and the implementation of new integrated library system software. All these changes came while they operated yet again with an unfilled deanship.

Libraries will always face unexpected events. A collective response can make the difference between merely reacting to change and helping to move an organization to a new and better place. What is more, such collective responses can benefit the day-to-day work of library organizations in noncrisis times as well.

\section{A Model of (Shared) Self-Leadership [A head]}

The model of expanded and shared self-leadership that this library employs has developed over several years. The process is iterative and evolving. It was not created with the intent of centralizing or asserting control. Instead, it was an attempt at improving communication and building sustainable relationships between library employees as a means to find new solutions to old problems. Further, this library collectively decided it needed a more nimble organization to anticipate and bridge transition periods between deans. Although top-down management is the conventional operating system in most academic settings, this library's employees had been 
disappointed and frustrated by a brief stretch of heavy-handed management. Additionally, in the wait between deans, strategic planning and long-term decision-making were often delayed, and the library's programs suffered as a result.

To address the need for a continuous and deliberate managerial process, two committees formed in 2018: a group of faculty volunteered to review and revise the library's bylaws to create a new structure that incorporated shared leadership, while a second group, comprised of both faculty and staff, was tasked with developing a strategic plan. The strategic plan was requested by the college administration but was also critical in establishing stability for the library. With a solid plan, employees will understand — and have contributed to — the work that will lead them into the future, thus lessening the reliance on the consistent leadership of a single dean. These two groups are examples of effective committee work; they developed their respective projects collectively, with support and oversight from the interim dean, but without the dean's direct supervision. Members of both committees have remained active and invested in the new work. The strategic plan began with ideas that had been collected previously; later in the process, staff had the opportunity to contribute. The bylaws team, too, shared drafts with the full library work group. The final version of the strategic plan was presented in a dedicated department meeting that was facilitated by an outside consultant to walk people through the plan and start to establish the norms necessary to collaborate effectively and move the plan forward.

The initial aim of the leadership model (as seen in revisions to the bylaws) was to expand participation in library department meetings by allowing all library staff, as well as faculty, to vote in meetings and otherwise take a more active part in the organization. Expanding participation allows the library to capitalize on a broader range of viewpoints and experiences; collectively the staff group is, in key ways, more diverse than the faculty-only group. Members 
of the staff, for example, can offer firsthand perspectives on what it is like to be a first-generation college student, a person of color, or an immigrant at this institution.

This model of self-leadership is an effort to articulate a shared purpose and to establish cohesion and well-being in a sometimes divided staff group. But the process has revealed other, less obvious benefits that are far-reaching. While these ideas were, initially, intuitive, they are supported with evidence from management and other related fields. For some, it is intuitive that people will find it meaningful to participate in the governance of their workplace. Building on this idea, Greg Stewart, Stephen Courtright, and Charles Manz note that the concept of selfleadership has appeared in management literature for decades. Their study distinguishes between an individual's self-leadership and the self-leadership of teams (more akin to the model described in this article). They further differentiate between a top-down model (where management tells a team they have to lead themselves) and a more organic version (again, more like the model described in this article). None of these is wholly good (or wholly bad), but Stewart, Courtright, and Manz review several studies and present some strengths and weaknesses. $^{2}$

Daan van Knippenberg, Lisa Nishii, and David Dwertmann link self-leadership to what they call a "business case for diversity." 3 One might intuit that a more diverse work group offers the opportunity for more hands to solve more problems as they arise. Here, too, the results are not as straightforward as they might seem. Stephanie Duchek, Sebastian Raetze, and Ianina Scheuch investigate the value of diverse work groups for the resiliency of an organization, while Van Knippenberg and his coauthors hypothesize about how diverse teams can help organizations build synergy. ${ }^{4}$ Both studies find that diverse workplaces come with challenges. For example, change can be slow. What is more, such organizations must strike a balance between the 
"informational resource perspective" (more ideas leading to more innovative solutions) and the "intergroup tension perspective," which finds that greater diversity can lead to increased misunderstanding and conflict. ${ }^{5}$ Both studies find that successful diverse teams promote the sharing of information and so enhance decision-making. Duchek, Raetze, and Scheuch warn that poorly managed workplace diversity can also lead to increased job dissatisfaction and conflicts that arise from misunderstandings. Organizations must show that they truly value diversity and open communications, but they also must lead their diverse teams with care. Van Knippenberg, Nishii, and Dwertmann find that accountability at all levels has proved effective. It can take the form of conventional reporting (for example, filing reports such as those required by the Equal Employment Opportunity Commission), but it can also result informally when advisers or advocates hold key players to task.

The leadership change solution in this library was practical. Such coming together enabled the library to harvest the existing expertise of its faculty and staff to benefit its internal operation. Margaret Wheatley's book Finding Our Way explains that knowledge is created internally and by individuals through their engagement with, and in relationship to, the world and their workplace. Knowledge - as opposed to theory (for example, management strategies or stepby-step guides that do not work) — cannot be generated independently of a relationship with an event, an idea, a context, or another person. It is a process: knowledge matures over time. ${ }^{6}$

The committee structure is closely linked to the development of the library's strategic plan. The plan identifies priorities central to the library's operation which, in turn, helped determine the creation of the committee structure. The committees differ from, but run parallel with, an extant structure based in "service units," each led by a unit head whose leadership role is incorporated into their job description. The old and new structures sometimes overlap; when they 
do, the unit oversees operations for that section, while the committee focuses on strategic planning.

Faculty and staff are urged—but not required — to volunteer their time in one or, at most, two committees per academic year, each of which meets for one hour per month. Committees elect their chair and secretary on an annual basis with the idea that these rotating positions are open to anyone interested. The chairs of each committee also serve on the Executive Council. The council is led by and advises the dean and includes all unit heads, for a total of 14 members. It requires an additional one-hour meeting per month. In addition, committee members do varying amounts of work outside their regular meetings. The library employs approximately 50 full-time employees, divided about equally between faculty and staff. Six committees were established, and 36 people initially participated, with between 7 and 11 members on each committee.

Ideally, this new structure and the resulting departmental organization would receive institutional recognition and provide the library with a stronger, collective voice within the university. A dean who supports this leadership model can also confidently represent the department on campus, secure in the backing of the staff group. As this library set out to create a more inclusive self-leadership structure, the employees wanted to make sure that an unsupportive dean would not undo their work and revert to a more traditional leadership style. The intention was to put in place a leadership model that would establish a lasting structure of increased autonomy within the constraints of the existing institutional governance structure. At this institution, departments are governed via bylaws; each department's bylaws must comply with those of the college and the larger university system. Further, all department bylaws must be ratified by the College Senate, composed of students, faculty, and staff. The most significant 
revisions advocated by the library's bylaws committee were to extend department membership to all faculty and staff, and to develop an active and robust committee structure. Work began on the formal bylaws in fall 2018; final ratification by the Senate occurred in November 2020, following several postponements due to the coronavirus pandemic.

\section{Self-Organizing Requires New Ways of Thinking [B head]}

Wheatley speaks repeatedly of how a shift in meaning is necessary for change to occur. Such revisions take place when current beliefs fall short and make clear the need for a new and different understanding. ${ }^{7}$ For organizations, the change process should be driven by a clear, collective direction (as opposed to a list of fixed goals or objectives), which, in turn, can create conditions for new interests and beliefs to thrive and take root. "The path of self-organization can never be known ahead of time. There are no prescribed stages or models," says Wheatley. She continues, "Leaders begin with a strong intention, not a set of action plans." ${ }^{8}$ Her observations resonate with the process described in this article.

Like self-organization, ongoing self-leadership is a process rooted in an openness to new ways of thinking, along with a tolerance for chaos and not knowing. This process requires a willingness to look beyond established principles and protocols (for example, to allow experimentation) as a means to solve problems. To feel comfortable in such an open-ended process, people need to trust and respect one another, as well as care for the purpose of their work. Their shared purpose will lend meaning to all aspects of the organization, and if people can see and understand their own role in the process, they will more likely engage, learn, and share information.

The pandemic has forced individuals and organizations around the globe to think on their feet. In this particular library, it has also tested the strength and flexibility of the organizational 
model recently put in place. A structure that under normal circumstances would require considerable time, trust, and commitment to function had to work in a context that was completely unexpected and new to everyone. Despite the collaborative and increasingly transparent nature of this process, effective and ongoing engagement of the participants has proved difficult to maintain. In addition to the increased workload, committee chairs (as new leaders) lack training in how to engage their committees, and established norms are absent overall. Work at home orders came in late March 2020, and the library staff group remains separated into the 2020-2021 academic year. This distancing comes when it might have been useful for committee members and the department as a whole to meet regularly in person.

The vision of self-leadership at this library was initiated by a shared realization that the existing system had outlived its purpose. The concept was largely based on the assumption that if given the opportunity, people would choose to engage. The reality has proved more complicated. Although well-intended and mutually agreed upon in principle, engagement and full participation have been challenging to translate into reality. The organization still struggles to better understand what inspires people to take part.

The employee group will need to focus current and future attention in three key areas: building trust, improving listening and communication, and developing transparency. The three are interrelated but develop differently and require different kinds of engagement by participants. Regardless of the challenges, all library organizations — and the people employed in them — will likely benefit from increased trust, a better exchange of information, and a more open way of operating. The next section offers examples of how these values look as they are developed and refined in an organization. This process is necessarily a long one, but even midway, positive results are evident. 


\section{Building Trust Takes Patience [B head]}

In an inclusive self-leadership structure that aims for broad participation, trust-based

relationships become particularly important, but many organizations struggle with how to build them. In the studies Ava Tress cites, people will more likely engage in their work if they feel trusted, empowered, and valued by their supervisor, coworkers, and organization. Factors that foster such feelings include organizational support; the significance of an employee's job; their sense of autonomy, flexibility, or both; the perceived fairness of supervisors; the degree to which people can participate in the decision-making process; and the level of trust that exists between coworkers and supervisors. ${ }^{9}$ The new committee structure in this library asks participants to have confidence not only in the committee structure but also in one another.

Developing trust is slow and sometimes difficult work, demanding patience on the part of all involved. adrienne maree brown suggests that organizational change should "move at the speed of trust," a concept she borrows from Mervyn Marcano and Stephen Covey. ${ }^{10}$ Wheatley, too, stresses the need for patience, perhaps more so with the shift to self-organization: "Selforganization is a long-term exploration requiring enormous self-awareness and support." The process is lengthy partly because self-organization "represents such a fundamentally different way of thinking about organization." Echoing brown, Wheatley also reinforces that "all changes in organization take much longer than we want to acknowledge." ${ }^{11}$ It is, therefore, reasonable to expect that, even with additional preparation and training, such evolution will come slowly; building sustainable relationships takes time, and patience will be required by everyone involved. Communication Demands Listening [B head]

At this library, one explicit purpose in developing a new leadership model was to expand participation and to share leadership and policy making across all ranks. With the traditional 
hierarchical structures that exist within academic institutions, librarians often feel "outranked" by faculty (even in institutions like this one, where librarians are considered faculty), and staff often feel looked down upon. For some, committee work promises the opportunity to influence the library's management, planning, and operations. Others may see such work as extra unpaid duties added to their job description, or responsibilities "above one's pay grade." The reality of academe and academic libraries may mean that some positions are continually under-recognized, inadequately compensated, or both.

At this institution, problems are compounded by multiple distinct job definitions set by two separate unions that represent library employees. Conversation about what can be asked of various employee groups is ongoing and will likely require guidance from the Office of Human Resources or input from union representatives. Brianna Marshall, Dani Brecher Cook, and Cinthya Ippolit's 2020 book, Fostering Change, looks at issues associated with this hierarchy within libraries. The book suggests that those who are not in power but have something to say should work twice as hard, build alliances, practice before they speak, and essentially perform extra labor to gain a voice. ${ }^{12}$ The authors of this article do not agree with that solution, but there are no easy remedies.

Historically, adherence to strict hierarchy has created a general lack of comprehension of the many structural differences between coworkers. With limited reason or encouragement for collaborative exchange, there has been no need to know. It now seems necessary for all library employees to better understand these differences. Tackling the sociocultural behavioral patterns will also require breaking old habits and learning new approaches for those involved. People in traditional positions of authority must support those who have stepped into the newly defined 
committee leadership roles, and employees who have previously been excluded from the decision-making process must seize the opportunities provided by the new, more inclusive rules.

The new committee structure asks for a collective commitment to a long-term creative process. Openness to risk-taking is essential, as colleagues are asked to develop trusting relationships where there may have been none before and to embrace a new organizational system that is being created collectively, on the fly. Listening becomes a key element in this process and an important skill for all participants. As this responsive and collaborative way of working continues to evolve, it will inevitably have to find ways to correct itself: concepts or solutions that function well for a specific period or task may require minor adjustments or complete revisions. Continuous communication and active listening thus become central to participation in this process.

As collaborators in a self-led department, faculty and staff at this library continue to engage in different layers of the work but now do so with more deliberate face-to-face time (albeit solely online while the pandemic continues). The exchanges between different ranks and labor groups have increased significantly. The hope is that, over time, new levels of trust and understanding will develop, and communication and cooperation can take place with greater ease, as people become used to interacting in recurring committee meetings.

Collective Decision-Making Requires Transparency [B head]

At this library, there was a collective and organic shift in focus to improve internal communications and to work toward greater self-determination. On the surface, transparency helps provide for equal access to information and decision-making, and must be actively cultivated and practiced in support of the collective decision-making process. At the institution described, a college-wide license to the business communication platform Microsoft Teams 
provided a logical repository for all committee-related materials. However, openness requires more than the right tools. It demands of all participants a new way to think about working. For example, meeting minutes and other important documents and plans must be read and approved by the appropriate committee or committees, then filed and stored. Further, interested members of the library community must read materials as needed. Admittedly, this leads to more work and requires ongoing engagement.

The collective decision-making process itself continues to evolve. The general idea is that committees can recommend new programs, policies, or procedures, which are then discussed, shaped, or possibly ratified by the full staff in monthly meetings. Many projects under consideration are reviewed or discussed in the Executive Council before being presented to the staff. As well, the Executive Council may identify issues that require attention and assign them to one or more committees. Thus far, committees and the full staff have engaged in discussions, rather than definitive votes. However, per the bylaws, all in the staff group have an equal vote.

Van Knippenberg and his coauthors borrow the term process accountability from psychology and define it as teams being held "accountable for how they arrived at a certain outcome." ${ }^{13}$ Process accountability, then, creates a transparency that enables participants to see the process by which decisions are made. This visibility fosters trust (and thus engagement) and also helps develop future leaders. Seeing and understanding the process helps others feel comfortable taking on responsibilities.

\section{Assessing the Process [A head]}

The library work group continues to wrestle with the process. They struggle to determine how to report and share information effectively, for example, and how much it is reasonable to expect committee members to read in advance of a meeting or project. Work from home orders have 
compounded these challenges, as they have hindered colleagues from learning from each other and truly getting to know one another in person.

As the committee structure evolves over time, this group will need to develop best practices to form a more stable framework on which employees may rely. Set schedules for meetings and reporting protocols can help guide the process as a whole. The requirement, at this library, of an annual report that summarizes each committee's work at the end of the academic year gives the Executive Council an understanding of the department's general direction.

This model aims to remain fluid and responsive, and it is critical that the employee group reflect annually on its collective accomplishments and goals. To that end, as the second academic year of this new committee structure began, the Executive Council endorsed an assessment of the effectiveness of this new model of leadership that also focused on the founding values of inclusivity and self-determination. A small subcommittee was formed to develop a framework for the assessment and to implement it. It devised a multiphase iterative process that relied heavily on the voices of the participants and sought to listen through multiple channels. The subcommittee began with a brief Qualtrics survey administered to all members of the staff during a department meeting. In the following meeting, a summary of survey results was shared with the full group, and three key questions were posed to initiate discussion. Such exchanges have proved an important part of the assessment process, allowing all to hear what their colleagues say and to reflect on their own beliefs and feelings. Such discussions will continue for several more meetings, as the conversation itself has proved transformative. In keeping with the iterative nature of this process, the subcommittee will follow up with a brief self-assessment survey conducted within each committee, with the intention of advancing productive and reflective conversation within these groups. This collaborative reflection has helped foster a similar 
discussion-focused shift in Executive Council meetings, too. Such exchanges promote trust and openness that can lead to more creative solutions.

These important, trust-building conversations are supplemented with an analysis, also conducted by the assessment subcommittee, that compares committees' annual reports with the goals outlined in the strategic plan. The annual reports serve as public barometers for how well the work, both underway and completed, relates to the strategic plan.

Since the committee structure is expected to evolve over time, this self-assessment will help the Executive Council as it continues to further the library's aspiration to become more inclusive and to specifically address such issues as trust, listening, and transparency. The establishment of best practices, such as setting meeting schedules and basic reporting protocols, including annual reports, seems rudimentary but will help form a more stable framework, offering dependability and openness. Lessons and insights from this assessment can evolve into future tasks for specific committees to build upon or even be incorporated into a revised strategic plan.

Like the format of the committees' annual reports, this inaugural year's assessment is a model; future iterations may look different. Other library employees will conduct the review, and the review itself will reflect the changes and issues that the library faces that year.

This group has largely avoided a default to more familiar, if ineffective, practices. In fact, with rising issues now directed to the relevant committee or committees, the problem-solving process has become faster and more collaborative. Further, committees can address unanticipated challenges that have arisen as a result of the pandemic. As the library responds to severe budget cuts and staff attrition, coordinated strategic and operational changes have been made to collection development, and conversations about succession planning have been initiated. The 
new structure has also proved valuable as the department plans for reopening after the pandemic. Each committee can identify and share strategic perspectives on the library's operation, space, and staffing. Such key information will then, in turn, provide an informed voice in future communication with the administration.

The employee group has gained important collective experience as people continue to participate in the evolution of their new leadership structure, and the process has revealed farreaching benefits. Trust in the committee work and, by extension, in one another has allowed new and direct channels of communication to be established between committee members who had few reasons to interact in the past. Despite the increased physical distance imposed by remote work, informal discussions have taken place between people who previously had little opportunity to meet and talk in person. The pandemic, too, has provided chances to rethink library practices. At the end of the fall 2020 semester, library committees discussed what worked well during that time and how those improvements might be preserved after the library reopens. These conversations take into account both library operations and the well-being of the employees. Committee chairs hear from more voices, many speaking openly and personally; these discussions can then influence the future of this workplace. As well, these discussions deepen relationships and influence the internal conversation in the library. As trust builds, and communication and access to information improve, the learning process becomes more entrenched.

\section{Questions Will Keep the Process Going [A head]}

This library strongly desired more leadership opportunities for faculty and staff. To that end, the new structure accounts for an annual opportunity for all members to change their committee membership, and for committee chairs and secretaries to step aside in favor of sharing these 
opportunities. The end of the first year of this new structure came in the midst of the pandemic, however, when the library was still closed and all continued to work from home. In the interest of continuity, the Executive Council recommended that all committee membership and leadership remain in place for a second year, and the full staff agreed.

That said, there are concerns that shifting annually might be too frequent. If projects are not completed in a single year, could they be left to languish, or even terminated by a new committee? When a committee has a mix of established and new members, will the new members' voices be heard? Will there be more engagement, or less? Many people choose their committee membership based solely on their current work; does this mean that committee membership is less likely to shift? Will people actually change committees or take up the leadership mantle? Is there something to be gained by keeping people in place for longer than one year?

At the end of 2020, the pandemic remained a big part of this case study. The pandemic's greatest contribution may be what it has taught this library staff group about itself: that it has pivoted, responded, and continued its operation despite remote work, retirements, and severe budget cuts, while also simultaneously implementing a new leadership structure. Although the combination of these circumstances is extreme by any measure, large and small library organizations around the country have found a range of differing solutions to their own problems. Just as no single handbook could have anticipated the drastic changes brought by the pandemic, no set of guidelines could successfully and continuously address the hundreds of unanticipated adjustments, big and small, that any library must make during a normal year. The true insight here is not what exact steps an organization can take to prepare for anticipated problems, but rather how the specific circumstances of any situation can inform development or 
draw on existing expertise. Organizations should remain free to explore a range of new ideas, approaches, resources, and strategies to unexpected and old problems alike.

All library work groups have already started this change process; they need only recognize the work that they are doing as such. The pandemic has already affected all organizations. In some cases, these changes may be temporary, but in other cases, groups may adopt some of these new procedures for the longer term. In finding new solutions, individuals and organizations - whether they embark on internal leadership change or not - must admit that they cannot know or control all their steps forward and that they must trust one another as well as the process itself to reach their goals.

Stephanie Margolin is an associate professor and the instructional design librarian at Hunter College Libraries, part of the City University of New York in New York City; she may be reached bye-mailat:smargo@hunter.cuny.edu.

Malin Abrahamsson is a higher education officer and the acquisitions manager and copyright assistant at Hunter College Libraries, part of the City University of New York in New York City; she may be reached by e-mail at: mab0007@hunter.cuny.edu.

\section{Notes}

1. For the purpose of this article, dean indicates the individual who is dean, chief librarian, and head of the library. It is an appointed position; the library does not have an elected chair, as many academic departments do. 
2. Greg L. Stewart, Stephen H. Courtright, and Charles C. Manz, "Self-Leadership: A Multilevel Review," Journal of Management 37, 1 (2011): 185-222, https://doi.org/10.1177/0149206310383911. Discussion of Charles Manz and Henry Sims is on page 185 .

3. Daan van Knippenberg, Lisa H. Nishii, and David J. G. Dwertmann, "Synergy from Diversity: Managing Team Diversity to Enhance Performance,” Behavioral Science \& Policy 6, 1 (2020): 75-92, here 76, https://doi:10.1353/bsp.2020.0007.

4. Stephanie Duchek, Sebastian Raetze, and Ianina Scheuch, “The Role of Diversity in Organizational Resilience: A Theoretical Framework," Business Research 13, 2 (2020): 387423, https://doi.org/10.1007/s40685-019-0084-8; Van Knippenberg, Nishii, and Dwertmann, "Synergy from Diversity."

5. Van Knippenberg, Nishii, and Dwertmann, "Synergy from Diversity," 78-79.

6. Margaret Wheatley, Finding Our Way: Leadership for an Uncertain Time (San Francisco, CA: Berrett-Koehler, 2007), 105.

7. Ibid., 61, 76-77.

8. Ibid., 38 .

9. Ava Tress, The Effect of Empowering Leadership on Work Engagement in an Organizational Change Environment: An Investigation of the Mediating Roles of Self-Efficacy and SelfEsteem (Hamburg, Germany: Anchor Academic, 2017).

10. adrienne maree brown, Emergent Strategy: Shaping Change, Changing Worlds (Chico, CA: AK Press, 2017), 42.

11. Wheatley, Finding Our Way, 56. 
12. Brianna Marshall, Dani Brecher Cook, and Cinthya Ippoliti, Fostering Change: A TeamBased Guide (Chicago: Association of College and Research Libraries, 2020), 4-5, http://www.ala.org/acrl/sites/ala.org.acrl/files/content/publications/booksanddigitalresources/ digital/FosteringChange.pdf.

13. Van Knippenberg, Nishii, and Dwertmann, "Synergy from Diversity," 85, attributes this to Jennifer S. Lerner and Philip E. Tetlock's "Accounting for the Effects of Accountability," Psychological Bulletin 125, 2 (1999): 255-75. 